\title{
Obez çocuk ve adolesanlarda vücut kitle indeksi ve biyoelektrik impedans yöntemi ile ölçülen vücut yağ oranının lipid düzeyleri ve metabolik parametrelerle ilişkisi
}

\author{
The relationship of body mass index and body fat ratio (measured using bioelectric \\ impedans) with lipid levels and metabolic parameters in obese children and adolescents
}

\author{
Rıza Taner Baran
}

Gönderilme tarihi: 05.04.2018

Kabul tarihi: 13.07 .2018

\begin{abstract}
Özet
Amaç:Bu çalışma ile obez çocuklarda biyoelektrik impedans yöntemi ile saptanan vücut yağ oranının (VYO), vücut kitle indeksi standart sapma (VKI-SDS) ve bel kalça oranına (BKO) kıyasla istenmeyen lipid profili ve metabolik parametreleri öngörmede etkinliğinin değerlendirilmesi amaçlandı.

Gereç ve yöntem: Bu çalışmaya 57 obez, 35 sağlıklı çocuk dahil edilmiş olup, boy standart sapma skoru (BSDS), ağırlık standart sapma skoru (ASDS), VKİ-SDS, BKO hesaplandı. Biyoelektrik impedans yöntemi ile VYO saptandı. Hastaların kan basınçları, glükoz, insülin, total kolesterol (TK), trigliserid (TG), yüksek dansiteli lipoprotein (HDL), düşük dansiteli lipoprotein (LDL) ve homeostatik model değerlendirme insülin direnci (HOMAIR) seviyeleri değerlendirildi.

Bulgular: Obez çocuk grubunda, VKI-SDS, BKO, VYO, sistolik ve diyastolik kan basıncı, TG, TK, LDL, insülin ve HOMA-IR değerleri kontrol grubuna göre daha yüksek bulundu ( $p \leq 0.05)$. HDL ve glükoz değerleri yönünden gruplar arasında fark saptanmadı ( $p>0.05$ ). Pearson korelasyon analizinde VKI-SDS, VYO, BKO ile sistolik ve diyastolik kan basıncı, insülin, HOMA-IR, TK, TG, LDL arasında pozitif ilişki varken, HDL ve glükoz ile arasında ilişki gözlenmedi.

Sonuç:Metabolik bozukluk ve dislipidemiyi öngörmek açısından BİA yöntemi ile tespit edilen VYO'nın, VKİSDS'ye göre daha üstün olmadığı, VKİ-SDS'nin ise BKO'na göre daha iyi olduğu saptandı. VKI-SDS ve VYO'nun beraber kullanımının obeziteye bağıı gelişebilecek hipertansiyon, metabolik bozukluk ve kardiyovasküler komplikasyonları önlemek açısından çok daha önemli olabileceği sonucuna varıldı.
\end{abstract}

Anahtar sözcükler: Lipid düzeyi, çocuk ve adolesan, vücut kitle indeksi, vücut yağ oranı, biyoelektrik impedans

Baran RT. Obez çocuk ve adolesanlarda vücut kitle indeksi ve biyoelektrik impedans yöntemi ile ölçülen vücut yağ oranının lipid düzeyleri ve metabolik parametrelerle ilişkisi. Pam Tıp Derg 2018;11(3);261-267.

\begin{abstract}
Purpose: To assess the predictive values of body fat ratio (BFR) in comparison to the body mass index (BMI)SDS and waist-to-hip ratio (WHR) in the evaluation of dyslipidemia and metabolic parameters in obese children and adolescents.

Materials and methods:Study included 57 obese and 35 healthy controls. Height standard deviation score (HSDS), weight standard deviation score (WSDS), WHR and BMI-SDS were calculated. Body fat ratio was measured using bioelectrical impedance. Blood pressure, plasma fasting glucose, fasting insulin, total cholesterol (TC), triglyceride (TG), high density lipoprotein (HDL), low density lipoprotein (LDL) and HOMA-IR were evaluated.

Results:The BMI-SDS, WHR, BFR, systolic and diastolic blood pressure, TG, TC, LDL, fasting plasma insulin and HOMA IR was higher in obese group compared to controls $(p<0.05)$. There was no statistically significant difference between the HDL and plasma fasting glucose level of obese and control group $(p>0.05)$. Correlation analysis revealed a positive correlation between BMI-SDS, BFR, WHR and TG, TC, LDL, insulin, and systolic and diastolic blood pressure, while there was no correlation with HDL and glucose.

Conclusion: There is no superiority of BFR to the BMI and WHR in predicting metabolic parameters and dyslipidemia of obese children and adolescents. BMI-SDS was found more predictive than WHR for dyslpidemia. However, using a combination of BMI and BFR might be much more useful in the evaluation of obesity and related complications including hypertension, cardiovascular and metabolic parameters.

Key words:Dyslipidemia, children and adolescent, body mass index, body fat ratio, bioelectrical impedance
\end{abstract}

Baran RT. The relationship of body mass index and body fat ratio (measured using bioelectric impedans) with lipid levels and metabolic parameters in obese children and adolescents. Pam Med J 2018;11(3):261-267.

Rıza Taner Baran, Dr. Antalya Eğitim Araştırma Hastanesi Pediatrik Endokrinoloji Kliniği, ANTALYA, e-posta: barantaner@yahoo.com (orcid. org/0000-0003-3776-9975) 


\section{Giriş}

Obezite, vücut yağ dokusunun aşırı miktarda artması olarak tanımlanır. Yapılan epidemiyolojik çalışmalarda hem çocuklarda hem de erişkinlerde sıklığının artmakta olduğu gösterilmiştir. Dünya çapında yaklaşık \%10 çocuğun fazla kilolu, 5 yaş altı 22 milyon çocuğun da obez olduğu tahmin edilmektedir [1]. Adolesan dönemde obez olan bireylerin hayatları boyunca obez olma olasılığının yüksek olduğu gösterilmiştir [2]. Obezite, kişiyi fiziksel ve psikolojik olarak etkilediği gibi ileri yaşlarda lipid metabolizması bozukluğu, arteriyel hipertansiyon, ateroskleroz, karaciğer yağlanması, hipertansiyon ve diabet gelişme riskini de arttırır [1].

Obezitenin değerlendirilmesinde kullanılan en yaygın yöntem vücut kitle indeksidir. Dünya Sağlık Örgütü, fazla kilonun sınıflandırılmasında vücut kitle indeksinin (VKI) kullanılmasını önermektedir [3]. Ayrıca deri kıvrım kalınlığı, bel kalça oranı (BKO) ve bel çevresinin (BÇ) ölçülmesi ve bunların birinin veya birden fazlasının kullanılmasının, kardiyovasküler riski öngörebilmek açısından önemli olduğu bildirilmiştir $[4,5]$.

VKİ, kardiyovasküler risk açısından önemli olan vücut yağ kitlesi, yağ yüzdesi ve yağ dağılımı hakkında bilgi vermez. Bazı çalışmalarda BKO'nun kardiyovasküler ve metabolik risk açısından daha önemli olduğu belirtilse de, çalışmalar arasındaki farklılıklar daha ileri araştırma yapmayı gerektirmektedir [6-9].

Biyoelektrik impedans analiz (BIA) yöntemi, hem yetişkinler hem de çocuklarda kullanılabilir. Uygulama kolaylığı, tekrar edilebilir olması, hızlı, güvenilir, ucuz ve girişimsel olmaması nedeniyle vücut bileşiminin değerlendirilmesinde kullanılan en etkin yöntemler arasındadır [10]. Farklı dokular farklı iletkenliğe sahiptir. BİA vücuda verilen akımdaki voltaj düşmelerini kaydederek vücut yapısının rezistansını ölçer. Bu yöntemle vücuttan geçen elektrik akımlarının hızı ve gücü ölçülür. Elektrik akımları kan, idrar, kaslar gibi su miktarı fazla olan dokulardan kemik, yağlar ve hava gibi diğer dokulara nazaran daha kolay geçer. Böylece kişilerin yağ miktarı ve oranı ile ilgili değerlendirme yapılmasını sağlar [11]. Ancak, vücut yağ oranının (VYO) klinik kullanımının önemi ayrıntılı olarak çalışılmamıştır.
$\mathrm{Bu}$ çalışmanın amacı, obez çocuk ve adolesanlarda BİA yöntemiyle ölçülen VYO'nun klinik önemini ve VKi-SDS, BKO gibi antropometrik parametrelere göre istenmeyen lipid profili, kan basıncı, HOMA-IR gibi metabolik parametreleri öngörmede daha etkin olup olmayacağını araştırmaktır.

\section{Gereç ve yöntem}

Bu çalışmaya, Ocak-Haziran 2016 tarihleri arasında Sağlık Bilimleri Üniversitesi Antalya Eğitim ve Araştırma Hastanesi pediatrik endokrinoloji polikliniğine başvuran 57 obez ve 35 sağlıklı çocuk dahil edildi. Diabet, inflamatuvar hastalıklar, enfeksiyon hastalıkları gibi kronik hastalıkları olan ve oral antidiabetik ilaç, insülin, antihipertansif ilaç ve lipid düşürücü ilaç kullanan hastalar çalışmaya dahil edilmemiştir.

Çalışma Helsinki Deklarasyon ilkelerine uygun olarak gerçekleştirilmiş olup Antalya Eğitim ve Araştırma Hastanesi yerel etik kurulundan etik onay alınmıştır. Orijinal ölçümleri yapmak ve tıbbi kayıtlarını gözden geçirmek için tüm hastalardan ve ebeveynlerinden bilgilendirilmiş onamlar alınmıştır.

Hastaların boy ve ağırlıkları hafif kıyafetli ve ayakkabısız olarak Harpenden statiometer ile ölçüldü. VKI, vücut ağırlığı boyun karesine bölünerek hesaplandı $\left(\mathrm{kg} / \mathrm{m}^{2}\right)$. BSDS, ASDS, VKi-SDS Türk çocukları için oluşturulan standartlara göre hesaplandı [12]. Sağlıklı kontrol grubuna VKi 5 persantil ile 85 persantil arası (VKI-SDS $-1,+1$ arası) olanlar, obez grubuna 95 persantil ve üstü (VKí-SDS +2 ve üstü) olanlar alındı. Pubertal değerlendirme Tanner evrelemesine göre yapıldı [13]. Bel çevresi elastik olmayan mezura ile ayakta son kostanın alt sınırı ve leğen kemiğinin üst noktası ortasından ekspiryum sonunda ölçüldü.

Vücut kompozisyonunu belirlemek için yapılan biyoelektrik impedans analiz Tanita body compocition analyzer MC-180MA 8- contact electrode system (Tanita Corp., Tokyo, Japonya) cihazı kullanılarak üretici firmanın standardize edilmiş değerlerine göre sabah 8.00-10.00 arasında yapıldı. Katılımcılardan ölçümden 12 saat öncesine kadar ağır egzersiz yapmamaları istendi. Yağ oranları (\%) yaş, cins, boy ve kilo bilgilerine göre hesaplandı. Kan basıncı en az 5 dakikalık istirahat sonrası oturur vaziyette ve üç ölçümün ortalaması olarak alındı. 
Laboratuvar değerlendirmede, glükoz seviyeleri, ticari olarak temin edilebilen bir kit (Beckman AU5800; Beckman Coulter Diagnostics, Brea, CA, ABD) kullanılarak hekzokinaz yöntemiyle ölçüldü. İnsülin seviyeleri kemilüminesan analizi (AccessDxl800; Beckman Coulter Inc., Brea, CA, ABD) kullanılarak belirlendi. Glükozile hemoglobin ( $\mathrm{HbA} 1 \mathrm{c})$ seviyeleri ticari olarak temin edilebilen kitler ve yüksek performanslı sıvı kromatografisi (Tosoh HLC 723 G8, Tosoh Bioscience, Tokyo, Japonya) kullanılarak belirlendi. Serum TG, TK, HDL ve LDL, alanin aminotransferaz (ALT), aspartat aminotransferaz (AST) ve kreatinin düzeyleri bir otoanalizör (Beckman AU5800; Beckman Coulter Diagnostics, Brea, CA, ABD) kullanılarak belirlendi. HOMA-IR açlık kan şekeri (mmol /L) açlık insülini (IU/mL)/22,5 formülü ile hesaplandı.

İstatistiksel analiz, SPSS Statistics for Windows yazılım sürümü 18,0 (SPSS Inc. Chicago, IL, ABD) tarafından gerçekleştirilmiştir. Varyansların eşitliği için Levene testi ve verilerin normallik dağılımı için Shapiro-Wilk testi kullanıldı. Tanımlayıcı istatistikler kategorik değişkenler sayı, yüzde ve sayısal değişkenler için ortalama, standart sapma, ortanca, minimum ve maksimum olarak ifade edildi. Grup karşılaştırmasında verilerin dağılımı normal olmadığı için Mann Whitney $U$ testi yapıldı. Korelasyon analizinde Pearson korelasyon testi kullanıldı. İstatistiksel anlamlılı $p<0.05$ olarak kabul edildi.

\section{Bulgular}

Bu çalışmaya 57 obez ve 35 kontrol olmak üzere 92 çocuk ve adolesan dahil edildi. Obez grubun yaş aralığı 10.28-18 yıl, yaş ortalaması $14.67 \pm 1.91 \mathrm{yıl}$ iken kontrol grubunun yaş aralığı 9.8-17.6 yıl, yaş ortalaması $15.5 \pm 1.8 \mathrm{yıld}$. Obez hasta grubunun VKİSDS: $3.1 \pm 0.43$, kontrol grubunun VKI-SDS $0.00 \pm 0,72$ idi.

Erkek/kız oranı obez grupta \%34/\%66, kontrol grubunda $\% 43 / \% 57$ idi ve gruplar arasında fark yoktu ( $p>0.358)$. VKI-SDS, BKO, VYO, sistolik ve diyastolik kan basıncı, TG, TK, LDL, insülin ve HOMA-IR değerleri obez grupta daha yüksekti ( $p \leq 0.05)$. HDL ve glukoz değerleri yönünden gruplar arasında fark yoktu $(p>0.05)$ (Tablo 1).

Pearson korelasyon analizinde VKİ-SDS, VYO, BKO ile sistolik ve diyastolik kan basıncı, insülin, HOMA-IR, TK, TG, LDL arasında pozitif ilişki varken, HDL ve glükoz arasında ilişki yoktu.

VKİ-SDS ile sistolik kan basıncı, HbA1c, TK, TG arasında zayıf (r:0.2-0.4), insülin, HOMA-IR, LDL, diyastolik kan basıncı ve BKO arasında orta (r:0.4-0.6), VYO ile arasında güçlü bir ilişki vardı $(r>0.8)$.

BKO ile sistolik kan basıncı arasında çok zayıf $(r<0,2)$, diyastolik kan basıncı, insülin, HbA1c, TK, TG, LDL, HbA1c, VYO arasında zayıf (r:0.2-0.4) ilişki vardı.

VYO ile sistolik ve diyastolik kan basıncı, HbA1c, TK, TG, BKO arasında zayıf (r:0.2-0.4), insülin, HOMA-IR, LDL arasında orta (r:0.4-0.6), VKİ-SDS arasında güçlü ( $r>0.8)$ bir ilişki vardı (Tablo 2).

\section{Tartışma}

Bu çalışmada, obez çocuk ve adolesanlarda BİA yöntemi ile saptanan VYO'nun lipid profili ve metabolik bozukluğu öngörmek açısından önemi ve VKİ-SDS'ye göre üstün olup olmadığı araştırıldı. VYO ve VKİ-SDS'nin lipid profili (HDL, glukoz hariç) ve metabolik parametrelerle (sistolik ve diyastolik kan basıncı, insülin, HOMAIR) pozitif ilişkisi olduğunu saptandı. Ancak, bu iki parametrenin birbirine üstünlüğü olmadığı ve beraber değerlendirilmelerinin obeziteye bağlı ileride olabilecek muhtemel komplikasyonları önlemek açısından daha faydalı olabileceği düşünüldü.

Obezite, yağın vücuda fazla depolanmasıdır ve hipertansiyon, koroner kalp hastalığı, diabetes mellitus, hepatobilier hastalık, arteriel hipertansiyon ve insülin ile ilişkisi gösterilmiştir [14].

Çocuk ve adolesanlarda obezitenin lipid bozukluğu ile ilişkisini araştıran çalışmalar vardır [15-24]. Obez bireylerde dislipideminin sebebi yağ dokusunun lipolizinden sorumlu bir enzim olan hormon duyarlı lipazın, insülin tarafından inhibe edilmesidir [25]. Brezilya'da 1234 çocuk ve adolesanda yapılan bir çalışmada, lipid bozukluğunun fazla kilolu ve obez çocuklarda daha sık olduğu gösterilmiştir [15]. Bir çalışmada obez çocuklarda kolesterol hariç, belirgin şekilde lipid düzeylerinde bozulma olduğu bildirilmişken [16], morbid obez erişkinlerde yapılan bir başka çalışmada VKI'nin TG ile pozitif, HDL ile negatif ilişkisi olduğu gösterilmiştir [21]. Onis ve ark. [22], 
Tablo 1. Obez ve kontrol grubunun klinik ve biyokimyasal verileri

\begin{tabular}{|c|c|c|c|c|}
\hline & & Obez & Kontrol & $p$ \\
\hline Sayı (n) & & 57 & 35 & \\
\hline Erkek / kız (\%) & & $34 / 66$ & $43 / 57$ & .358 \\
\hline Yaş (yıl) & & $14.67 \pm 1.91$ & $15.45 \pm 1.81$ & .275 \\
\hline \multicolumn{5}{|c|}{ Antropometrik ölçümler } \\
\hline & BSDS & $0.37 \pm 0.96$ & $-0.03 \pm 1.04$ & .037 \\
\hline & ASDS & $3.18 \pm 0.75$ & $-0.15 \pm 0.89$ & .000 \\
\hline & VKi-SDS & $3.10 \pm 0.43$ & $0.00 \pm 0.72$ & .000 \\
\hline & BKO & $0.85 \pm 0.10$ & $0.75 \pm 0.04$ & .000 \\
\hline SKB (mmHg) & & $118.79 \pm 10.84$ & $112.60 \pm 7.48$ & .005 \\
\hline DKB (mmHg) & & $77.26 \pm 7.87$ & $69.25 \pm 6.43$ & .000 \\
\hline \multicolumn{5}{|c|}{ Laboratuvar Değerleri } \\
\hline & Glükoz (mg/dL) & $89.87 \pm 9.25$ & $88.11 \pm 10.49$ & .202 \\
\hline & İnsülin (mlu/mL) & $17.90 \pm 9.32$ & $7.18 \pm 3.81$ & .000 \\
\hline & HOMAIR & $4.10 \pm 2.06$ & $1.74 \pm 1.32$ & .000 \\
\hline & HbA1c (\%) & $5.44 \pm 0.45$ & $5.23 \pm 0.29$ & .023 \\
\hline & TK (mg/dL) & $161.81 \pm 37$ & $136.20 \pm 21.37$ & .000 \\
\hline & TG (mg/dL) & $125.95 \pm 69.15$ & $80.98 \pm 39.51$ & .001 \\
\hline & HDL (mg/dL) & $45.53 \pm 7.72$ & $48.28 \pm 12.87$ & .193 \\
\hline & LDL (mg/dL) & $94.49 \pm 26.36$ & $65.43 \pm 19.02$ & .000 \\
\hline VYO (\%) & & $38.89 \pm 6.69$ & $19.43 \pm 6.34$ & .000 \\
\hline
\end{tabular}

BSDS: boy standart sapma skoru; ASDS: kilo standart sapma skoru; VKi: vücut kitle indeksi, SDS: standart sapma skoru; BKO: bel kalça oranı; SKB: sistolik kan basıncl; DKB: diastolik kan basıncı, LDL: düşük dansiteli lipoprotein, HDL: yüksek dansiteli lipoprotein, HOMA: homoestasis model değerlendirme, IR: insülin direnci; VYO: vücut yağ oranı

Tablo 2. Metabolik parametrelerle vücut yağ oranı, VKI-SDS ve bel kalça oranının korelasyon analizi

\begin{tabular}{lccc}
\hline & $\begin{array}{c}\text { VKi-SDS } \\
\boldsymbol{r}(\boldsymbol{P})\end{array}$ & $\begin{array}{c}\text { BKO } \\
\boldsymbol{r}(\boldsymbol{P})\end{array}$ & $\begin{array}{c}\text { VYO } \\
\boldsymbol{r}(\boldsymbol{P})\end{array}$ \\
\hline SKB (mmHg) & $0.301(0.003)$ & $0.155(0.145)$ & $0.252(.012)$ \\
DKB (mmHg) & $0.422(0.000)$ & $0.250(0.017)$ & $0.368(0.00)$ \\
Glükoz (mg/dL) & $0.077(0.451)$ & $0.182(0.086)$ & $0.005(0.96)$ \\
İnsülin (mlu/mL) & $0.551(0.000)$ & $0.339(0.001)$ & $0.471(0.00)$ \\
HOMA-IR & $0.516(0.000)$ & $0.362(0.000)$ & $0.453(0.00)$ \\
HbA1c (\%) & $0.263(0.009)$ & $0.244(.020)$ & $0.220(0.03)$ \\
TK (mg/dL) & $0.353(0.000)$ & $0.266(0.011)$ & $0.398(0.00)$ \\
TG (mg/dL) & $0.332(0.001)$ & $0.351(0.001)$ & $0.296(0.00)$ \\
HDL (mg/dL) & $-0.128(0.210)$ & $-0.170(0.11)$ & $-0.072(0.48)$ \\
LDL(mg/dL) & $0.504(0.000)$ & $0.387(0.000)$ & $0.452(0.00)$ \\
VKİ-SDS & & $0.573(0.000)$ & $0.814(0.00)$ \\
VYO (\%) & $0.828(0.000)$ & $0.395(0.000)$ & $0.395(0.00)$ \\
BKO & $0.569(0.000)$ & &
\end{tabular}

SKB: sistolik kan basıncl; DKB: diastolik kan basıncI, HOMA: Homoestasis model değerlendirme, IR: insülin direnci; TK: total kolesterol; TG: trigliserid HDL: yüksek dansiteli lipoprotein LDL: düşük dansiteli lipoprotein VKI: vücut kitle indeksi, SDS: standart sapma skoru; VYO: vücut yağ oranı BKO: bel kalça oranı 
VKİ artışının HDL'de düşme ve plazma insülin, HOMA-IR, TG, ve LDL seviyesinde artışla ilişkili olduğunu bildirmişlerdir. Ancak, literatürde aksi çalışmalar da vardır [17, 18, 20, 23, 24]. Ricco ve ark.'nın [17] 6-18 yaş arası 37 fazla kilolu ve 50 obez hastada yaptıkları bir çalışmada kan basıncı, açlık glükozu, 2. saat glükozu, TK, HDL ve TG'yi karşılaştırmışlar ve hafif HDL yüksekliği dışında fark bulamamışlardır. Lima ve ark. [18], obez ve fazla kilolu çocuklar arasında lipid profili açısından fark gösterememişlerdir. Brezilya'da 1134 çocuk ve adolesanda yapılan bir çalışmada da VKI, deri kıvrım kalınlığı ve kalça boy oranının lipid profili ile ilişkili olmadığı belirtilmiştir [20].

Bizim çalışmamızda, sistolik ve diyastolik kan basıncı, TG, TK, LDL, insülin ve HOMA-IR değerleri obez grupta anlamlı şekilde yüksek bulunurken, HDL ve glükoz yönünden fark bulunamadı. Ayrıca korelasyon analizinde VYO ve VKİ-SDS ile sistolik ve diyastolik kan basıncı, insülin, HOMA-IR, TK, TG, LDL arasında pozitif korelasyon varken, HDL ve glükoz ile arasında korelasyon olmadığı görüldü.

VKI, BKO hesaplanmasının kolay olması ve çok yaygın kullanılmasına rağmen yağ ağırlığı ve yağ olmayan doku ağırığı hakkında bilgiler vermez. Biyoelektrik impedans analiz yöntemi ise vücut yağ ve kas miktarını daha iyi değerlendirmemizi sağlar. İstenmeyen lipid düzeylerini öngörmek açısından VYO, VKI-SDS ve BKO'nun hangisinin daha iyi bir parametre olabileceği ve birbirleriyle ilişkisini araştıran çalışmalar vardır [26-33]. Kobayashi ve ark.'nın [30], erişkin hasta grubuyla yaptıkları büyük ölçekli bir çalışmada VYO'nun, VKI'ye göre lipid profili ile daha güçlü ilişkisi olduğu gösterilmiştir. Oliosa ve ark.'nın [32] yaptığı bir çalışmada VYO'nun istenmeyen lipid profilini tahmin etmede VKI ve bel/boy oranından daha iyi olduğu bildirilmiştir. Rubira ve ark.'nın [33] genç erişkin kadınlarda yaptıkları bir çalışmada, obez grupta VKI ve VYO'nun, sistolik ve diyastolik kan basıncı ve lipid düzeyleriyle güçlü pozitif ilişkisi olduğu bildirilmiştir. Bizim çalışmamızda, VKİ-SDS ile sistolik kan basıncı, HbA1c, TK, TG arasında zayıf (r:0.2-0.4), insülin, HOMAIR, LDL, diyastolik kan basıncı, BKO arasında orta (r:0.4-0.6), VYO arasında güçlü bir ilişki $(r>0.8)$ vardı. Ayıca VYO ile sistolik ve diyastolik kan basıncı, HbA1c, TK, TG arasında zayıf (r:0.2-0.4), insülin, HOMA-IR, LDL arasında orta (r:0.4-0.6), VKI-SDS arasında güçlü bir ilişki ( $r>0.8)$ vardı. Bu durum iki parametrenin de lipid düzeyi ve metabolik durumla pozitif ilişkisi olduğunu ve birbirlerine üstünlüklerinin olmadığını göstermektedir.

Bazı çalışmalar BKO'nun VYO'yu yüksek oranda yansıttığı ve koroner kalp hastalığı riskini VKI'ye oranla daha iyi öngördüğünü bildirirken [26, 27], bir çalışmada çok etkili olmadığı belirtilmiştir [28]. Ketel ve ark. [29] erişkinlerde yaptıkları çalışmada, bel çevresi ölçümü ve deri kıvrım kalınlığının, dual-energy X-ray absorptiometry (DXA) ile tespit edilen vücut yağ kütlesini belirlemede en iyi yöntem olduğunu belirtmişlerdir. Yine bu çalışmada VYO'nun VKI'ye nazaran bel çevresi ile daha yakın ilişkisi olduğu gösterilmiştir [30]. Özhan ve Ersoy [34], obez çocuk ve adolesanlarda metabolik sendrom öngörülmesinde, VKİ-SDS, BKO, bel çevresi, bel boy oranı ve boya göre ağırlığın hangisinin daha iyi bir parametre olabileceğini araştırmışlar ve boya göre ağırlığın metabolik sendromu öngörmek açısından en iyi parametre olabileceğini bildirmişlerdir. Bizim çalışmamızda, VKİ-SDS'nin BKO'ya göre TK, TG, LDL, sistolik ve diyastolik kan basıncı, insülin, HOMA-IR ve VYO arasında daha güçlü pozitif ilişki gösterdiği görüldü.

Sonuç olarak, obez çocuk ve adolesanlarda metabolik bozukluk ve dislipidemiyi öngörmek açısından, BİA ile tespit edilen VYO'nun, VKİSDS'ye göre dahaüstün olmadığını, VKİ-SDS'nin ise BKO'ya göre lipid bozukluğunu öngörmek açısından daha iyi olduğunu düşünüyoruz. VKİ-SDS ve VYO'nun beraber kullanımının ise obeziteye bağlı gelişebilecek hipertansiyon, metabolik bozukluklar ve kardiyovasküler komplikasyonları önlemek açısından çok daha önemli olabileceği sonucuna vardık. İleride daha büyük hasta gruplarıyla yapılacak çalışmaların bu konuya ışık tutacağına inanmaktayız.

Çıkar İlişkisi: Yazarların çıkar ilişkisi olmadığını beyan ederim.

\section{Kaynaklar}

1. Kosti RI, Panagiotakos DB. The epidemic of obesity in children and adolescents in the world. Cent Eur $\mathrm{J}$ Public Health 2006;14:151-159.

2. Reichert FF, Baptista Menezes AM, Wells JC, et al. Physical activity as a predictor of adolescent body fatness: a systematic review. Sports Med 2009;39:279294. 
3. WHO Expert Committee. Physical status: the use and interpretation of anthropometry. WHO Technical Report Series no.854, 1995.

4. De Koning L, Merchant AT, Pogue J, Anand SS. Waist circumference and waist-to-hip ratio as predictors of cardiovascular events: meta-regression analysis of prospective studies. Eur Heart J 2007;28:850-856.

5. Krakauer NY, Krakauer JC Dynamic association of mortality hazard with body shape. Plos One 2014;9:e88793.

6. Ashwell M, Gunn P, Gibson S. Waist-to-height ratio is a better screening tool than waist circumference and BMI for adult cardiometabolic risk factors: systematic review and meta-analysis.Obes Rev 2012;13:275-286.

7. Mc Carthy HD, Ashwell M. A study of central fatness using waist-to-height ratios in UK children and adolescents over two decades supports the simple message 'keep your waist circumference to less than half your height. Int J Obesity 2006;30:988-992.

8. Kahn HS, Imperatore G, Cheng YJ. A population based comparison of BMI percentiles and waist to height ratio for identifying cardiovascular risk in youth. J Pediatrics 2005;146:482-488.

9. Savva SC, Lamnisos D, Kafatos AG. Predicting cardiometabolic risk: waist to height ratio or BMI. A meta analysis. Diabetes Metab Syndr Obes 2013;6:403-419.

10. Kaya $H$, Özçelik $O$. Vücut bileşimlerinin değerlendirilmesinde vücut kitle indeksi ve biyoelektrik impedans analiz metodlarının etkinliğinin yaş ve cinsiyete göre karşılaştııılması. FÜ Sağ Bil Tıp Derg 2009;23:1-5.

11. Webber J, Donaldson M, Allison S, MacDonald I. A comparison of skinfold thickness, body mass index, bioelectrical impedance analysis and dual energy $X$-ray absorbtiometry in assessing body composition in obese subjects before and after weight loss. Clin Nutr 1994;38:299-306.

12. Neyzi O, Bundak R, Gokcay G, et al. Reference values for weight, height, head circumference, and body mass index in Turkish children. J Clin Res Pediatr Endocrinol 2015;7:280-293

13. Tanner JM, Whitehouse RH. Clinical longitudinal standards for height, weight, height velocity, weight velocity, and stages of puberty. Arch Dis Child 1976;51:170- 179.

14. Huang XB, Hu R, Liu JL, et al. Relationship between body mass index, waist circumference and blood pressure among 5246 residents in Chongqing area. Zhonghua Xin Xue Guan Bing Za Zhi 2007;35:655-658.

15. Reuter CP, da Silva PT, Renner JD, De Mello ED, Valim AR, Pasa L, et al. Dyslipidemia is associated with unfit and overweight obese children and adolescents. Arq Bras Cardiol 2016;106:188-193.
16. Ding W, Cheng H, Yan Y, Zhao X, Chen F, Huang G. 10-year trends in serum lipid levels and dyslipidemia among children and adolescents from several schools in Beijing, China. J Epidemiol 2016;26:637-645.

17. Ricco RC, Ricco RG, Almeida CA, Ramos APP. Estudo comparativode fatores de risco em crianc, as e adolescentes com diagnós-tico antropométrico de sobrepeso ou obesidade. Rev Paul Ped 2010;28:320325.

18. Lima SC, Arrais RF, Almeida MG, Souza ZM, Pedrosa LF. Plasma lipid profile and lipid peroxidation in overweight or obese children and adolescents. J Pediatr (Rio J) 2004;80:23-28.

19. Huxley R, Mendis S, Zheleznyakov E, Reddy S, Chan J. Body mass index, waist circumference and waist:hip ratio as predictors of cardiovascular risk a review of the literature. Eur J Clin Nutr 2010;64:16-22.

20. Quadros TM, Gordia AP, Silva RC, Silva LR. Predictive capacity of anthropometric indicators for dyslipidemia screening in children and adolescents. J Pediatr (Rio J) 2015;91:455-463.

21. Shamai L, Lurix E, Shen M, Novaro GM, Szomstein S, Rosenthal R. Association of body mass index and lipid profiles: evaluation of a broad spectrum of body mass index patients including the morbidly obese. Obes Surg 2011;21:42-47.

22. Onis M, Martínez Costa $C$, Núnez F, Nguefack-Tsague G, Montal A, Brines J. Association between WHO cut offs for childhood overweight and obesity and cardiometabolic risk. Pub Health Nut 2013;6:625-630.

23. Burcu Doğan, Can Öner. Obez bireylerde iki farklı yöntemle hesaplanan vücut yağ oranının antropometrik değerler ve lipid parametreleri ile ilişkisi. FNG \& Bilim Tıp Dergisi 2015;1:124-128.

24. Weinbrenner T, Schröder H, Escurriol V, Fito M, Elosua $\mathrm{R}$, Vila $\mathrm{J}$, et al. Circulating oxidized LDL is associated with increased waist circumference independent of body mass index in men and women. Am J Clin Nutr 2006;83:30-35.

25. Haemmerle G, Lass A, Zimmermann R, Gorkiewicz G, Meyer C, Rozman J. Defective lipolysis and altered energy metabolism in mice lacking adipose triglyceride lipase. Science 2006;312:734-737.

26. Nambiar S, Hughes I, Davies PS. Developing waist to height ratio cut offs to define overweight and obesity in children and adolescents. Public Health Nutr. 2010;26:1-9.

27. Siavash M, Sadeghi M, Salarifar F. Comparison of body mass index and waist/height ratio in predicting definite coronary artery disease. Ann Nutr Metab 2008;53:1626.

28. Freedman DS, Katzmarzyk PT, Dietz $\mathrm{WH}$, et al. Relation of body mass index and skinfold thicknesses to cardiovascular disease risk factors in children: the Bogalusa Heart Study. Am J Clin Nutr 2009;90:210216. 
29. Ketel IJ, Volman MN, Seidell JC, et al. Superiority of skinfold measurements and waist over waist to hip ratio for determination of body fat distribution in a population-based cohort of Caucasian Dutch adults. Eur J Endocrinol 2007;156:655-661.

30. Kobayashi J, Murano S, Kawamura I, Nakamura F, Murase Y, Kawashiri MA. The relationship of percent body fat by bioelectrical impedance analysis with blood pressure, and glucose and lipid parameters. J Atheroscler Thromb 2006;13:221-226.

31. Nagaya T, Yoshida $H$, Takahashi $H$, Matsuda $Y$, Kawai M. Body mass index (weight/height2) or percentage body fat by bioelectrical impedance analysis: which variable better reflects serum lipid profile? Int J Obes Relat Metab Disord 1999;23:771-774.

32. Oliosa PR, Zaniqueli D, Alvim RO, Barbosa MCR, Mill JG. Body fat percentage is better than indicators of weight status to identify children and adolescents with unfavorable lipid profile. J Pediatr (Rio J) 2018 Jan 5 pii: S0021-7557(17)30758-1.

33. Rubira MC, Rubira AP, Rubira LA, Lıma MC, Franco RJ, Colombo FM. Blood pressure and lipid profile in young women: the role of anthropometric measurement. Rev Bras Educ Fís Esporte, (São Paulo) 2014;28:553-560.

34. Özhan B, Ersoy B. The importance of weight for height in prediction of metabolic syndrome in obese children and adolescents: impact of gender and puberty. Pam Med J 2017;10:23-32. 